\title{
Comparison of Recurrence of Intranasal Polyps Treated with Intranasal Polypectomy versus Steroid Use
}

\author{
Dr Sanaullah Bhatti Dr Muhammad Hassan Nisar Dr Sharif Shahid Dr Sabeen Sajida \\ ENT Department Nishtar Hospital, Multan
}

\begin{abstract}
Objective: To compare recurrence of intranasal polyps treated with intranasal polypectomy versus steroid use. Study Settings and Duration: ENT department Nishtar hospital Multan from 24 ${ }^{\text {th }}$ December 2017 to 23 June 2018. Study design: randomized controlled trial Material and methods: All 50 cases were divided in two groups M and S. Group $\mathrm{M}$ were given oral prednisone (30-60 mg) for 15-20 days in tapering regimen while patients in S group, intranasal polypectomy done. Information was collected through pre-designed Performa. Mean and standard deviation was calculated for quantitative variables such as age. Frequencies and percentages were calculated for qualitative variables such as gender and outcome variable i.e. recurrence. Chi-square test was applied to compare recurrence in both groups and $\mathrm{P} \leq 0.05$ was considered as significant. Results: The mean age of patients in group A was $34.49 \pm 6.51$ years and in group B was $34.15 \pm 6.97$ years. Male were $64.44 \%$ and $35.56 \%$ were females with ratio of 1.81:1. The mean duration of disease in group A was $5.81 \pm 4.33$ days and in group B was $5.75 \pm$ 4.56 days. Recurrence rate in Group A (steroid group) was $57.78 \%$ while in Group B (intranasal polypectomy group) was $22.22 \%(p=0.001)$ Conclusion: Intranasal polypectomy is more effective in terms of non-recurrence of nasal polyps as compared to steroid use in the management of nasal polyps.
\end{abstract}

Keywords: Nasal polyps, non-recurrence, medical treatment, polypectomy.

DOI: $10.7176 / \mathrm{JMPB} / 60-06$

Publication date:October $31^{\text {st }} 2019$

\section{INTRODUCTION}

Abnormal lesions which are resulted from different types of diseases mechanisms within intra nasal cavity arising from mucosal surface of the nasal cavity or one or more than one paranasal sinuses are termed as nasal polyps. Nasal polyps are often found at the outflow tract of the sinuses ${ }^{1}$. Children with allergic rhinitis, allergic fungal sinusitis or chronic sinusitis are prone the development of nasal polyps in their nasal cavity. A polyp by nature could any of the following; antral-choanal polyp, malignant or benign tumor or a massive benign polyp ${ }^{2}$.

Patient present with the complaints of nasal obstruction, watery rhinorrhea, sneezing, itchy eyes, anosmia and headache. ${ }^{3}$ On examination with nasal speculum or endoscope, smooth, grey, glossy lesions hanging from narrow stalk are seen. Nasal polyps are soft, mobile and non-tender on palpation. Diagnosis is confirmed by coronal CT scan with bone window. ${ }^{4}$

Almost 4 percent of the population is affected by nasal polyps making it a highly common finding. Recurrence of the polyposis is very common with severe disease reported up to $10 \%$ of patients. Reoccurrence of polyps is quite common with medical treatment. Occurrence of nasal polyps in male to female ratio in adult population is approximately 2:4:1. Occurrence of multiple polyps usually happens in patients older than 20 years and is most commonly found in age group of 40 or above years. Nasal polyps rarely occur in children younger than 10 years.

Management of nasal polyposis consists of medical therapy and surgery. Medical options vary and include topical and oral steroids. Polypectomy and functional endoscopic sinus surgery are the available surgical treatments of nasal polyps. ${ }^{5}$ Polypectomy seems to represent a valuable procedure and it is first-hand surgical procedure for treating nasal polyps. ${ }^{6}$

Elimination or nasal polyps and symptoms of rhinitis and to establish olfaction and nasal breathing and prevention of recurrence of nasal polyps are few objectives considered when starting medical management of nasal polyposis i.e. glucocorticosteroids. Medical management of nasal polyposis has evident effect on signs and symptoms of nasal polyps. In mild cases of nasal polyps steroids can be used as long term therapy as alone or in combination for severe cases of nasal polyp alongwith systemic steroids or surgery. Use of systemic steroids also known as medical polypectomy has beneficial effect on all signs and symptoms' including sense of smell etc. but it is still not considered as a definite mode of treatment of nasal polyps. Owing to the risk of adverse effects related to long term use of steroids these are usually recommended in short term cases only ${ }^{7}$.

Long-term use, presents a risk of hypothalamic-pituitary-adrenal axis suppression, cataract formation, growth retardation, nasal bleeding, and, nasal septal perforation. ${ }^{8}$ and long term use is contraindicated in patients with asthma, diabetes and in hypertension. ${ }^{9}$

The patient may require surgical intervention if severe symptoms of obstruction and infection prove refractory to medical treatment. Surgical treatment includes simple removal with snare/Tilley Henckle's forceps or removal of polyps using FESS technique ${ }^{10,11}$. Previous literature has shown that in patients with higher load of sinunasal polyps, surgical polypectomy can result in extensive reduction in polyps and thus can lead in betterment in quality 
of life and nasal obstruction.

The rationale of comparing steroid use in comparison with intranasal polypectomy for the treatment of nasal polyps is that Nishtar hospital is a tertiary care hospital giving health facilities to many people living in that area, so this study would be helpful for patients suffering from nasal polyps by giving them a definitive, cost effective and better treatment of their problem.

\section{Material and Method}

This study is a randomized control trail. It was conducted in Otorhinolaryngeology Department of Nishtar Hospital Multan from $1^{\text {st }}$ December 2017 to $1^{\text {st }}$ June 2018. Ethical approval for this study was obtained from Hospital Ethics Committee. A total of 50 patients were added to the study after getting informed consent. Sample size was calculated using the reference study conducted by AA Malik ${ }^{14}$. Non probability consecutive type of sampling technique was used to collect the sample. Inclusion criteria was as follows; Signs and symptoms of nasal polyps or chronic rhinosinusitis requiring polypectomy, abnormalities on CT scan confirming the diagnosis of chronic rhinosinusitis or nasal polyps, patients aged 18 or older. Patients already using systemic corticosteroids or other medication influencing nasal mucosa during the study, patients with previous nasal surgery in past 6 weeks, history of ASA intolerance, pregnancy, cystic fibrosis, serious concurrent disease were excluded from the study. All fifty patients were divided into two equal groups, $\mathrm{M}$ and $\mathrm{S}$ with 25 patients in each. Polyps were graded from 0 to 3 on the basis of its growth and morphology where $0=$ no polyps, $1=$ mild polyposis, $2=$ moderate polyposis and $3=$ severe polyposis.

All patients in Group M were given oral prednisone (30-60 mg) for 15-20 days in tapering regimen while in group S patients, intranasal polypectomy was done. Polypectomy was performed by same surgeon in all patients. The patients were followed at $4^{\text {th }}$ ( $1^{\text {st }}$ visit $), 8^{\text {th }}\left(2^{\text {nd }}\right.$ visit) and $12^{\text {th }}\left(3^{\text {rd }}\right.$ visit) week after initiation of treatment and examined clinically in OPD to see the recurrence of nasal polyp. The information was collected through predesigned Performa. Computer software SPSS version 23 was used to analyze the data. Mean and standard deviation was calculated for quantitative variables such as age. Frequencies and percentages were calculated for qualitative variables such as gender and outcome variable i.e. recurrence. Chi-square test was applied to compare recurrence in both groups and $\mathrm{P} \leq 0.05$ was considered as significant.

\section{Results:}

Mean age of all the patients was $32.56 \pm 7.23$ years. Both groups consisted of 25 patients each with male to female ratio of 1.5:1. On pretreatment visit, grade 1, 2and 3 polyps were seen in 8,12 and 5 patients of the medical group while in 7, 9 and 9 patients of surgical group, respectively $(\mathrm{p}=0.441)$. (Table-I) Before starting the treatment, nasal obstruction was present in 14 and 15 patients $(p=0.774)$, snoring was present in 18 and 16 patients $(p=0.544)$, postnasal drip was present in 9 and 13 patients $(\mathrm{p}=0.254)$, altered sense of smell was present in 12 and 17 patients $(\mathrm{p}=0.152)$ in medical and surgical groups, respectively. Table-II

At $1^{\text {st }}$ post treatment visit, grade 0,1 and 2 polyps were observed in 7, 12 and 6 patients of medical group, while in 16,7 and 2 patients of the surgical group ( $p=0.033$ ). No grade 3 polyps were seen in any group. (TableIII) At $2^{\text {nd }}$ post treatment visit, grade 0 and 1 polyps were seen in 12 and 13 patients of the medical group while in 20 and 5 patients of the surgical group $(\mathrm{p}=0.018)$ with no patients having grade 2 or grade 3 polyps. At $3^{\text {rd }}$ post treatment visit, grade 0 and 1 polyps were seen in 14 and 11 patients of the medical group while in 21 and 4 patients of the surgical group $(\mathrm{p}=0.031)$ with no patients having grade 2 or grade 3 polyps. Table-IV

At $3^{\text {rd }}$ post treatment visit, nasal obstruction was present in 7 and 4 patients $(\mathrm{p}=0.306)$, snoring was present in 9 and 6 patients $(p=0.355)$, postnasal drip was present in 8 and 11 patients $(p=0.382)$, altered sense of smell was present in 9 and 7 patients $(\mathrm{p}=0.544)$ in medical and surgical groups, respectively. Table-V

\section{Table-I}

Polyp grade at pre-treatment visit

\begin{tabular}{|l|c|c|c|}
\hline \multicolumn{1}{|c|}{ Polyp Grade } & Medical group & Surgical group & \multirow{2}{*}{ p-value } \\
\cline { 1 - 3 } 1 & $8(32 \%)$ & $7(28 \%)$ & \multirow{2}{*}{0.441} \\
\cline { 1 - 3 } 3 & $12(48 \%)$ & $9(36 \%)$ & \\
\cline { 1 - 3 } Total & $5(20 \%)$ & $9(36 \%)$ & \\
\hline
\end{tabular}


Table-II

Symptoms at pretreatment visit

\begin{tabular}{|l|c|c|c|}
\hline \multicolumn{1}{|c|}{ Symptom } & Medical group (n=25) & Surgical group (n=25) & p-value \\
\hline Nasal obstruction & $14(56 \%)$ & $15(60 \%)$ & 0.774 \\
\hline Snoring & $18(72 \%)$ & $16(64 \%)$ & 0.544 \\
\hline Postnasal drip & $9(36 \%)$ & $13(52 \%)$ & 0.254 \\
\hline Sense of smell & $12(48 \%)$ & $17(68 \%)$ & 0.152 \\
\hline
\end{tabular}

Table-III

Polyp grade at $1^{\text {st }}$ post-treatment visit

\begin{tabular}{|l|c|c|c|}
\hline Polyp Grade & Medical group $(\mathbf{n}=\mathbf{2 5})$ & Surgical group $(\mathbf{n}=\mathbf{2 5})$ & \multirow{2}{*}{ p-value } \\
\cline { 1 - 3 } 0 & $7(28 \%)$ & $16(64 \%)$ & \multirow{2}{*}{0.033} \\
\cline { 1 - 3 } & $12(48 \%)$ & $7(28 \%)$ & \\
\hline
\end{tabular}

Table-IV

Polyp grade at $2^{\text {nd }}$ and $3^{\text {rd }}$ post-treatment visit

\begin{tabular}{|c|l|c|c|c|}
\hline Visit & Polyp Grade & Medical group (n=25) & Surgical group (n=25) & p-value \\
\hline \multirow{2}{*}{$2^{\text {nd }}$} & 0 & $12(48 \%)$ & $20(80 \%)$ & 0.018 \\
\cline { 2 - 4 } & 1 & $13(52 \%)$ & $5(20 \%)$ & \\
\hline \multirow{2}{*}{$3^{\text {rd }}$} & 0 & $14(56 \%)$ & $21(84 \%)$ & \multirow{2}{*}{0.031} \\
\cline { 2 - 4 } & 1 & $11(44 \%)$ & $4(16 \%)$ & \\
\hline
\end{tabular}

Table-V

Symptoms at $3^{\text {rd }}$ post treatment visit

\begin{tabular}{|l|c|c|c|}
\hline \multicolumn{1}{|c|}{ Symptom } & Medical group (n=25) & Surgical group (n=25) & p-value \\
\hline Nasal obstruction & $7(28 \%)$ & $4(16 \%)$ & 0.306 \\
\hline Snoring & $9(36 \%)$ & $6(24 \%)$ & 0.355 \\
\hline Postnasal drip & $8(32 \%)$ & $11(44 \%)$ & 0.382 \\
\hline Sense of smell & $9(36 \%)$ & $7(28 \%)$ & 0.544 \\
\hline
\end{tabular}

\section{Discussion}

Semi translucent edematous masses in nasal and paranasal cavities are known as nasal polyps which most commonly originate from the mucosa of middle turbinate, the sinuses and middle nasal meatus, and prolapsed into the nasal cavity. The condition seems to result from an underlying pathology and histological analysis has shown evidence of the exudation and retention of albumin and tissue fluid, together with localized eosinophilic inflammation in the polyps.

Nasal polyposis is recurrent in many patients and requires several years of therapy. Even though, several studies have demonstrated that topical corticosteroids are effective in reducing the size of polyps, nasal obstruction symptoms after surgical treatment and the recurrent rate of polyps after polypectomy. Efficacy of various topical corticosteroids like fluticasone, Budesonide momatasone in respect to dose, duration of the treatment remains controversial issue. ${ }^{12}$

Mean age of the patients in current study is $32.56 \pm 7.23$ years. These findings are comparable to the mean age of the patients in studies conducted by Farrukh MS et al ${ }^{13}$ and Malik AA et al ${ }^{14}$. However mean age was 59 years in a study conducted by Punekar YS et $\mathrm{al}^{15}$. In contrast Rohail A (16) showed in their results that mean age was 25 years. In this study both groups consisted of 25 patients each with male to female ratio of 1.5:1 this is comparable to the multiple previous studies where nasal polyps were 2 times more prevalent in male as compared to female patients ${ }^{13-16}$. Although the male-to-female ratio is 2-4:1 in adults, the ratio in children is unreported.

Recurrence of polyp after at $3^{\text {rd }}$ visit in Group M (medical group) was seen in $11(44 \%)$ while in Group $\mathrm{S}$ (surgery group) was $4(16 \%)$ with p-value of 0.031 . In a study done by Malik AA et $\mathrm{al}^{14}$ has also concluded that surgical management is better than medical treatment for management of nasal polyps. They found recurrence of polyp after 3 months in $44 \%$ patients of steroid group and $10 \%$ of surgical group.

Short-term treatment courses of systemic steroid combined with long-term steroid intranasal spray led to satisfactory results in $85 \%$ of the patients, and the mean clinical severity index was reduced by $77.7 \% .{ }^{17}$ Punekar YS et $\mathrm{al}^{15}$ in a cohort consisted of 1,675 patients, of which, 576 patients were post-polypectomy steroid users and 1,099 patients were steroid non-users concluded that the patients with post polypectomy intranasal steroid use showed lower risk for a repeat polypectomy compared to steroid non-users.

Mygind $\mathrm{N}$ et $\mathrm{al}^{18}$ in his study has shown some different results. He concluded that although, intranasal and 
systemic steroids have shown more improvement in sense of smell as compared to surgical treatment but obstructed symptoms still persisted in majority of cases after complete course of medical treatment. Similarly, RohailA et al ${ }^{16}$ in his study concluded that recurrence rate is less after surgical treatment than medical treatment for management of nasal polyps. He showed initial response in $52.0 \%$ patients while $48.0 \%$ patients did not show any response after intranasal steroid therapy. After a follow up of 1 year, he has found recurrence rate of $82 \%$ in intransal steroid group and only $37 \%$ in surgical group. All these previous studies also support the results of our study that surgical treatment is more preferable option for these particular patients.

Nasal polyps are highly chronic in nature, as shown by the high recurrence rate in this study and in previous literature as well. Thus short term use of steroids has failed to control the recurrence of nasal polyps thus suggesting the use of combined treatment modalities including medical as well as surgical approaches in order to control the disease in long run ${ }^{19}$. On the whole, it is concluded that effectiveness (in terms of non-recurrence) of intranasal polypectomy is less compared to steroid use in the management of intranasal polyps.

Conclusion: The intranasal polypectomy is more effective in terms of non-recurrence of nasal polyps as compared to steroid use in the management of nasal polyps. So, we recommend that intranasal polypectomy should be used as a primary therapy in the management of nasal polyps for the prevention of its recurrence.

\section{Conflict of interest:}

There was no conflict of interest.

\section{Funding Source:}

No external funding source was used.

\section{REFERENCES}

1. DeConde AS, Mace JC, Levy JM, Rudmik L, Alt JA, Smith TL. Prevalence of polyp recurrence after endoscopic sinus surgery for chronic rhinosinusitis with nasal polyposis. Laryngoscope. 2017 Mar;127(3):550-5.

2. Stevens WW, Schleimer RP, Kern RC. Chronic rhinosinusitis with nasal polyps. J allergy Clin Immunol. 2016 Jul 1;4(4):565-72.

3. Wu AW, Ting JY, Platt MP, Tierney HT, Metson R. Factors affecting time to revision sinus surgery for nasal polyps: a 25-year experience. Laryngoscope. 2014 Jan;124(1):29-33.

4. Baig M, Hussain T. Recurrent ethmoidal polypi: a prospective study. J Rawal Med Coll. 2008;12(1):33-6.

5. DeConde AS, Mace JC, Levy JM, Rudmik L, Alt JA, Smith TL. Prevalence of polyp recurrence after endoscopic sinus surgery for chronic rhinosinusitis with nasal polyposis. Laryngoscope. 2017 Mar;127(3):550-5.

6. Sharma R, Lakhani R, Rimmer J, Hopkins C. Surgical interventions for chronic rhinosinusitis with nasal polyps. Cochrane Database System Rev. 2014(11).

7. Bozek A. Pharmacological management of allergic rhinitis in the elderly. Drugs Aging. 2017 Jan 1;34(1):218.

8. Rajguru R. Nasal polyposis: current trends. Ind J Otolaryngol Head Neck Surg. 2014 Jan 1;66(1):16-21.

9. Beswick DM, Gray ST, Smith TL. Pharmacological management of chronic rhinosinusitis: current and evolving treatments. Drugs. 2017 Oct 1;77(16):1713-21.

10. Head K, Chong LY, Hopkins C, Philpott C, Schilder AG, Burton MJ. Short-course oral steroids as an adjunct therapy for chronic rhinosinusitis. Cochrane Database System Rev. 2016(4).

11. Rimmer J, Fokkens W, Chong LY, Hopkins C. Surgical versus medical interventions for chronic rhinosinusitis with nasal polyps. Cochrane Database System Rev. 2014(12).

12. Kang IG, Yoon BK, Jung JH, Cha HE, Kim ST. The effect of high-dose topical corticosteroid therapy on prevention of recurrent nasal polyps after revision endoscopic sinus surgery. Am J Rhinol. 2008;22:497-501.

13. Farrukh MS, Rafique M. Recurrent Nasal Polyps: An Experience at Liaquat University Hospital Hyderabad and Civil Hospital Karachi. J Liaqat Uni Med Health Sci. 2013;12(03):195-7.

14. Malik AA, Usman F, Ashfaq AH, Ahmad N. Medical versus surgical treatment for early ethmoidal nasal polyps. Rawal Med J. 2012;37(3):309-12.

15. Punekar YS, Ahmad A, Saleh HA. Estimating the effect of nasal steroid treatment on repeat polypectomies: survival time analysis using the General Practice Research Database. Rhinology. 2011;49(2):190-4.

16. Rohail A, Malik MF, Awan AA. Comparison of conservative versus surgical treatment of ethmoidal nasal polyps. Pak J Med Health Sci. 2010;4(3):184-7.

17. Bonfils P, Nores J, Halimi P, Avan P. Corticosteroid Treatment in Nasal Polyposis with a Three-Year Followup Period. Laryngoscope. 2003;113:683-7.

18. Mygind N, Lund V. Intranasal Corticosteroids for Nasal Polyposis: Biological Rationale, Efficacy, and Safety. 
Treat Respir Med. 2006;5:93-102.

19. Vento SI, Ertama LO, Hytonen ML. Nasal polyposis: clinical course during 20 years. Ann Allergy Asthma Immunol. 2000;85(3):209-14. 